\title{
Emissivity of the popular dental materials
}

\author{
M. Dabrowski ${ }^{1}$, R. Dulski ${ }^{1}$, P. Zaborowski ${ }^{2}$, St. Zmuda ${ }^{3}$ \\ ${ }^{1}$ Institute of Optoelectronics, Military University of Technology, \\ ul. Kaliskiego 2, 00-908 Warsaw, Poland, rdulski@wat.edu.pl \\ ${ }^{2}$ Military Institute of the Health Services, ul. Szaserów 128, 00-909 Warsaw, Poland \\ ${ }^{3}$ Central Military Surgery, ul. Koszykowa 78, 00-911 Warsaw, Poland
}

\begin{abstract}
Knowledge of emissivity is essential to ensure high accuracy of temperature measurements when using non-contact methods. Emissivity coefficients were calculated using the reflective method. The authors introduce and compare average and spectral directional emissivity of the most popular dental materials in spectral bands commonly used in modern IR cameras.

The measurements of temperature in dentistry are important because of the fact that dental procedures can bring on uncontrolled increasing in temperature inside the oral cavity. It is known [1-3] that temperature increase inside the pulp of about $5^{\circ} \mathrm{C}$ can lead to irreversible changes in the pulp itself and thus can be very danger to patient's health. During examination of thermal injury of dental equipment in clinical circumstances we are interested in real temperature values rather than apparent ones [4, 5], which cannot be measured using IR cameras without knowledge of emissivity of observed objects.

This fact appears well in Fig. 1 where the apparent temperature distribution of four different dental materials placed on the homogeneous background is shown.

Unfortunately, most real materials including dental ones are selective. In such a case its emissivity depends on wavelength. Many people who use IR cameras are not familiar enough with IR technique and what's more, data about value of object's emissivity in real measurement conditions are often difficult to find in literature.
\end{abstract}

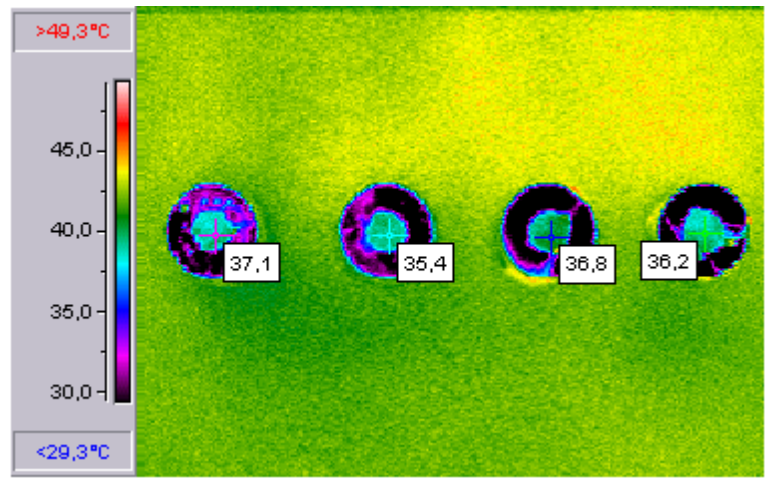

Fig. 1. Apparent temperature distribution of dental materials

Another problem is that the operating spectral band of IR camera depends on its design, especially on the detector's type (i.e., microbolometric FPA works in different spectral band than QWIP or PtSi ones) and the value of emissivity used for correction should be calculated in the same spectral band as operating spectral band of the IR camera used.

Spectral directional emissivity for each material was determined using the reflective method [7], i.e. indirectly by processing measured values of reflectance. 


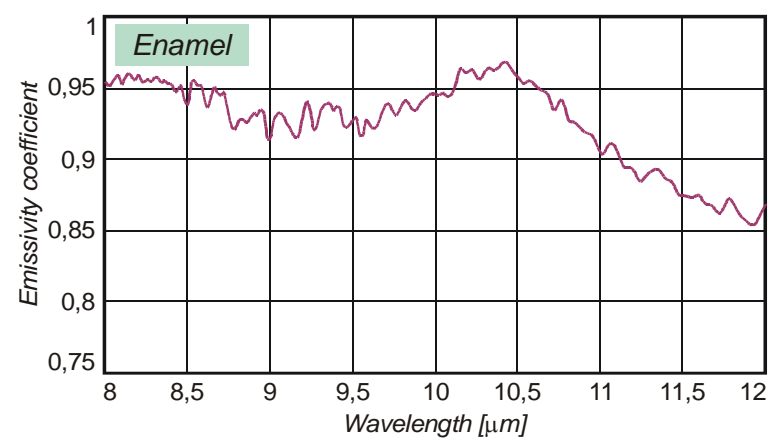

Fig. 2. Emissivity coefficient of the enamel

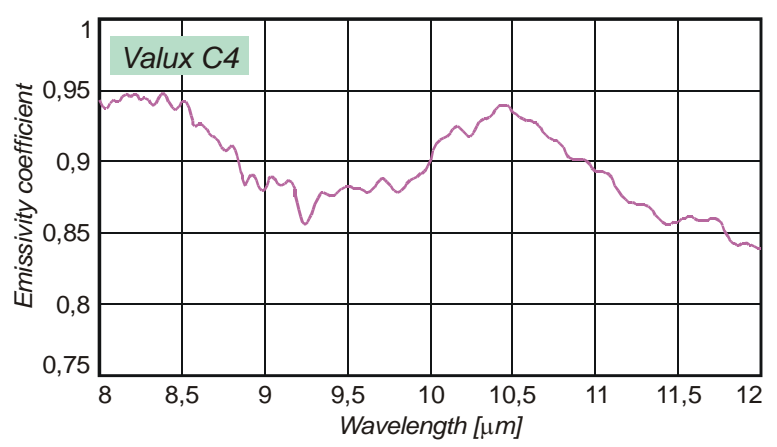

Fig. 3. Emissivity coefficient of an example dental material

Example results of the spectral directional emissivity calculations for the enamel and a dental material are shown in Fig. 2 and Fig. 3, respectively.

\section{References}

1. Zach L, Cohen G., Thermogenesis in operative techniques, comparisons of four methods, J Prosthet Dent 1962; 12:97784.

2. Noyborg H, Brannstrom J., Pulp reaction to heat, J Prosthet Dent 1968; 19:605-12.

3. Carson J, Rider T, Nash D., A thermographic study of heat distribution during ultra-speed cavity preparation, J Dent Res 1979; 48:1681-4.

4. M. Dąbrowski, R. Dulski, S. Żmuda, P. Zaborowski, C. Pogorzelski, The use of thermovision camera to represent physiological and pathological conditions of oral cavity mucous membrane, Infrared Physics \& Technology, 43 (2002) p. 265-269.

5. H. Madura, M. Dąbrowski, R. Dulski, S. Żmuda, P. Zaborowski, Thermographic method for evaluation of thermal influence of Nd:YAG laser on a tooth root during sterilization process, Infrared Physics \& Technology, 46 (2004) p. 167-171.

6. S. Żmuda, P. Zaborowski, P. Trykowski, M. Dąbrowski, R. Dulski, Effect of hte emission properites of detal materiale and hard detal tissues of the teeht on indirect temperature measurement of the teeth., Stomatologia Wspótczesna, Suplement nr 1/2000, p. 8-12 (in Polish).

7. Ascetta J.S., Shumaker D.L., eds, The Infrared and Electro-Optical Systems Handbook, SPIE Optical Engineering Press, Bellingham (1993). 